\title{
Novel Opposite Stirring Mode in Bloom Continuous Casting Mould by Combining Swirling Flow Nozzle with EMS
}

\author{
Haibo Sun ${ }^{1, * \mathbb{D}}$, Liejun $\mathrm{Li}^{2}$ and Chengbin Liu ${ }^{3}$ \\ 1 Department of Materials and Engineering, School of Materials Science and Energy Engineering, \\ Foshan University, Foshan 528000, China \\ 2 Institute of Metallic Materials Making and Shaping, School of Mechanical and Automotive Engineering, \\ South China University of Technology, Guangzhou 510640, China; liliejun@scut.edu.cn \\ 3 Manufacturing Department, Baowu Group Guangdong Shaoguan Iron and Steel Co., Ltd., \\ Shaoguan 512123, China; a28983@baosteel.com \\ * Correspondence: sunmyseven@126.com; Tel.: +86-137-5152-0889
}

Received: 30 September 2018; Accepted: 16 October 2018; Published: 18 October 2018

\begin{abstract}
The metallurgical performances in a mold cavity were investigated using a conventional bilateral-port nozzle or a swirling flow nozzle (SFN) plus with in-mold electromagnetic stirring (M-EMS) for bloom continuous casting (CC) process. To this end, a coupled model of electromagnetism, flow, and heat transfer was developed. Meanwhile, corresponding plant trials were conducted to evaluate the influence of a melt feeding mode on the internal quality of an as-cast bloom in Shaoguan Steel, China. Under the case of the SFN plus with M-EMS, a novel opposite stirring mode in the bloom CC mold cavity can be observed. A swirling flow in the anti-clockwise direction generated by the SFN, and the other swirling flow in the clockwise direction induced by the M-EMS were formed in regions with distances ranging from $0 \mathrm{~m}$ to $0.11 \mathrm{~m}$ and $0.218 \mathrm{~m}$ to $1.4 \mathrm{~m}$ from the meniscus, respectively. As compared to the case of the bilateral-port nozzle plus with M-EMS, the opposite stirring mode in the mold cavity can promote the melt superheat dissipation, improve the casting soundness and the componential homogeneity, inhibit the mold level fluctuation, and also be beneficial to prevent slag erosion for the nozzle external wall at the meniscus. Here, the fluctuation range of carbon segregation along the casting direction is reduced from 0.16 to 0.06 , and the magnitude of mold level fluctuation is reduced from $5.6 \mathrm{~mm}$ to $2.3 \mathrm{~mm}$ under the adoption of SFN plus with M-EMS, respectively.
\end{abstract}

Keywords: swirling flow nozzle; opposite stirring mode; M-EMS; superheat dissipation; level fluctuation

\section{Introduction}

In the continuous casting process, it is well known that the feeding mode of molten steel into a mold cavity has a significant influence on the strand quality [1,2]. To weaken the jet impingement depth and improve the superheat dissipation in the mold cavity, much work on the melt feeding mode has been carried out in recent years. Yokoya et al. [3,4] have inspected the swirling flow by fixing a swirl blade at the upper part of a normal straight nozzle to attain the superheat dissipation effect in the mold cavity. Marukawa et al. [5,6] applied a rotating electromagnetic field around the submerged entry nozzle (SEN) to generate a local melt swirling flow inside the nozzle. They indicated that the electromagnetic swirling flow nozzle can reduce the jet impinging depth and cause the meniscus temperature to increase. However, many potential practical problems, such as maintaining the swirling blade under erosion from high speed molten steel or the adhesion of inclusions $[5,7,8]$, and the limited 
space between the mold and the tundish for installation and maintenance of the electromagnetic stirrer, etc., will restrict their further application during the continuous casting (CC) process. Therefore, the present authors [9] designed a swirling flow nozzle (SFN) with outlets at the tangential direction for the bloom CC process, and demonstrated that the application of the SFN [10] is beneficial to the improvement of strand soundness.

To control the bulk flow favorably, in-mold electromagnetic stirring (M-EMS), a well established technology was widely applied in the CC process to enhance the columnar-to-equiaxed transition [11,12] and reduce the surface and subsurface defects by generating swirling flow in the designated area. Trindade et al. [13] presented coupled models to study the turbulent flow and solidification behaviors during the CC process. They pointed out that the M-EMS can improve superheat dissipation and weaken the invasion depth of the jet. Unfortunately, to gain a further melt superheat dissipation effect at the lower part of the mold by M-EMS, a strong rotational flow will accordingly be present near the meniscus, which may cause severe level fluctuation [14,15], and then give rise to slag entrapment at the meniscus, especially for the billet CC process [16]. Thus, the dual M-EMS [17,18] was proposed to inhibit the disturbance near the meniscus by generating an opposite stirring mode in the mold cavity. The magnetic shield technology [19] was put forward in succession. However, the investment and maintenance cost of the equipment is quite high, which will increase the cost of productions.

To address the above difficulties, an opposite stirring mode in the mold cavity innovatively generated by a combination of SFN and M-EMS for the bloom continuous casting is proposed. This is the easiest way to further enhance the metallurgical effect of M-EMS without investing in additional facilities for the CC process. In this work, the effect of the opposite stirring mode on melt flow pattern, level fluctuation, and heat transfer in the CC mold cavity has been numerically and experimentally investigated based on a curved five-strand bloom caster within a diameter of $12 \mathrm{~m}$ in Shaoguan Steel, China. Here, the morphologies of as-cast blooms were observed by acid etching, and the quantitative measurement of macro-segregation was tested by the wet chemical analyzer.

\section{Model Description}

\subsection{Assumptions}

The following assumptions are proposed to simplify the mathematical model and make it more efficient.

(1) The molten steel flow in the mold cavity is a steady-state, incompressible flow process. The density, the viscosity, and the specific heat were assumed to be constant over temperature.

(2) The influence of mold oscillation and mold curvature on the melt flow was not considered.

(3) Flux or slag layer was considered on top of the molten metal free surface only for insulation.

(4) The latent heat of the peritectic transformation and the joule heating generated by the induced current compared to the latent heat of fusion were considered to be negligible [12]. The mushy zone was treated as a porous medium, wherein the melt flow obeyed Darcy's law.

(5) The effect of melt flow on the electromagnetic field was ignored due to the small magnetic Reynolds number (about 0.01 [13]) in the stirring region.

(6) The iron core of the stirrer was assumed to be magnetically linear with a constant permeability [13]. The cooling water jacket of the CC mold, the stainless steel protective jacket of the EMS, and the other insulation material in the EMS device were all simplified as a paramagnet in this model.

\subsection{Macroscopic Transport Model}

Based on the assumptions above, all the transport equations for the incompressible and steady fluid flow can be given in the Cartesian coordinate as the following form.

$$
\nabla \cdot\left(\rho V_{i} \phi\right)=\nabla \cdot\left(\Gamma_{\phi} \nabla \phi\right)+S_{\phi}
$$


where $\phi$ represents the velocity, the enthalpy, the turbulent kinetic energy, or the turbulent energy dissipation rate of local molten steel. $\Gamma_{\phi}$ and $S_{\phi}$ are the diffusion coefficient and the source term of the variable of $\phi$, respectively. Table 1 lists the specific equations and variables for the macroscopic transport model.

Table 1. Transport equations and the variables involved.

\begin{tabular}{|c|c|c|c|c|}
\hline \multirow{2}{*}{ Models } & \multirow{2}{*}{ Equations } & \multicolumn{3}{|r|}{ Variables * } \\
\hline & & $\phi$ & $\Gamma_{\phi}$ & $S_{\phi}$ \\
\hline \multirow{4}{*}{ Fluid flow model } & Continuous & 1 & 0 & 0 \\
\hline & Momentum & $u_{i}$ & $\mu_{e f f}$ & $-\partial P / \partial i+\rho g_{i}+\mathbf{F}_{E}+S_{P}+f_{\sigma}$ \\
\hline & Turbulent kinetic energy & K & $\mu_{e f f} / \sigma_{K}$ & $\mathrm{G}-\rho \varepsilon$ \\
\hline & Turbulent energy dissipation rate & $\varepsilon$ & $\mu_{e f f} / \sigma_{\varepsilon}$ & $\frac{\varepsilon}{K}\left(C_{1} G-C_{2} \rho \varepsilon\right)$ \\
\hline Heat-transfer model & Enthalpy & $H$ & $k_{l}+\mu_{t} / P r_{t}$ & 0 \\
\hline
\end{tabular}

The electromagnetic force density, $\mathbf{F}_{E}$, as the source term of the momentum equations in the Table 1, can be calculated by solving Maxwell's and electromagnetic constitutive equations [20].

Gauss's law for magnetism:

$$
\nabla \times \mathbf{B}=0
$$

Ampere's law:

$$
\nabla \times \mathbf{B}=\mu_{0} \mu_{\mathrm{r}} \mathbf{J}
$$

Faraday's law:

$$
\nabla \times \mathbf{E}=-\partial \mathbf{B} / \partial t
$$

Ohm's law:

$$
\mathbf{J}=\sigma(\mathbf{E}+\mathbf{v} \times \mathbf{B})
$$

where $\mathbf{J}$ is the current density in the melt, $\sigma$ is the electric conductivity, $\mathbf{E}$ is the electric field intensity, $\mathbf{B}$ is the magnetic flux density, $\mathbf{v}$ is the melt velocity, $t$ is the time, $\mu_{0}$ and $\mu_{\mathrm{r}}$ are the vacuum and relative magnetic permeability, respectively. The instantaneous electromagnetic force density, $\mathbf{F}_{t}$, can be subsequently calculated by:

$$
\mathbf{F}_{t}=\mathbf{J} \times \mathbf{B}
$$

It is observed from Equation (6) that the electromagnetic force density changes over time, owing to the sinusoidal running current of the stirrer. Thus, the local time-averaged electromagnetic force density, $\mathbf{F}_{E}$, is employed in the post-process to investigate the electromagnetic field characteristics, and can be expressed as [21]:

$$
\mathbf{F}_{E}=\frac{1}{2}\left(\mathbf{F}_{r}+\mathbf{F}_{i}\right)
$$

where $\mathbf{F}_{r}$ and $\mathbf{F}_{i}$ are the real and imaginary parts of $\mathbf{F}_{t}$, respectively.

The $S_{P}$, as the other source term of momentum equation in the Table 1, can be calculated by Darcy's law, and is utilized to account for the effect of phase change on the convection and turbulence in the mushy region.

$$
S_{P}=A_{m u s h} \frac{f_{L}^{3}+\xi}{\left(1-f_{L}\right)^{2}}\left(u_{l}-u_{s}\right)
$$

where $u_{S}$ is the solid velocity due to the pulling of a solidified shell out of the domain (casting velocity). $A_{\text {mush }}$ is a constant coefficient (100,000 [13]) of mushy zone, $\xi$ is a very small positive number (such as 0.001 ) to avoid division by zero in the Equation (8). $f_{L}$ is the liquid fraction and will be discussed in the 
following solidification model. Meanwhile, the source term of surface tension, $f_{\sigma}$, in the momentum equations will be described in the following volume of fluid (VOF) model.

\subsection{Solidification Model}

To obtain a precise prediction of heat transfer and solidification, the total enthalpy $(H)$ for enthalpy formulation in the Table 1 can be split into sensible enthalpy $(h)$ and latent enthalpy $(\Delta H)$. The details are:

$$
H=h+\Delta H=h_{r e f}+\int_{T_{r e f}}^{T} c_{p} d T+f_{L} \cdot L
$$

where $c_{p}$ is the specific heat. $L$ is the latent heat of steel solidification. $f_{L}$ is the liquid fraction in each control cell and can be given as:

$$
f_{L}=\left\{\begin{array}{cc}
0 & T \leq T_{S} \\
\frac{T-T_{S}}{T_{L}-T_{S}} & T_{S}<T<T_{L} \\
1 & T \geq T_{L}
\end{array}\right.
$$

where $T_{L}$ and $T_{S}$ are the liquidus and solidus temperatures, respectively.

\subsection{VOF Model}

To precisely represent the profile of free surface, the VOF model pioneered by Hirt and Nichols [22] is used. In this model, volume fraction of molten steel, $f_{m}$, in a control cell over the all computational domain should satisfy the following conservation equation:

$$
\frac{\partial f_{m}}{\partial t}+u_{i} \frac{\partial f_{m}}{\partial x_{i}}=0
$$

where $0<f_{m}<1$ represents the steel/air interface. $f_{m}=1$ or 0 represents full or empty of molten steel, respectively.

The surface tension at the steel/air interface is considered to be a volume force as a function of the volume fraction, $f$. Based on the continuum surface force model, proposed by Brackbill [23], the curvature of the interface, $\kappa$, can be defined in terms of the divergence of a unit vector normal to the interface with the aid of the cell volume fraction $(f)$ and its gradient. Meanwhile, the addition of surface tension to the VOF calculation is treated as the body force source term, $f_{\sigma}$, in the momentum equation according to the divergence theorem. These can be expressed as:

$$
\kappa=-\nabla \cdot \frac{\nabla f}{|f|}, \quad f_{\sigma}=\sigma \frac{2 \rho \kappa \nabla f}{\rho_{a}+\rho_{m}}
$$

Moreover, the thermophysical properties, such as the density, the specific heat, viscosity, etc., appearing in the transport equations are determined by the presence of component phases in each control cell:

$$
\psi_{m} f_{m}+\psi_{a} f_{a}=\psi
$$

where $\psi$ represents the thermophysical property in each control cell. The subscript $a$ and $m$ represent denote the air and melt, respectively.

\subsection{Boundary Conditions and Computational Procedure}

\subsubsection{Boundary Conditions}

Figure 1 gives the geometric schematic and its inner manufacture mold of the SFN. Table 2 lists the main geometrical dimensions of the SFN and bilateral-port nozzle. Table 3 gives the thermal 
physical properties and boundary conditions employed in the coupled model. To insure the flow in the simulation process can be fully developed, the length twice over that of real mold has been taken as the length of the computational domain. The computational domain adopts a hexahedron element method in the meshing process. Here, fine meshes are applied to the interface region of the free surface for a better description of the local physical phenomena. The mesh number of the whole computational domain is approximately 1,900,000. The detailed boundary conditions employed in the coupled model are described as below.

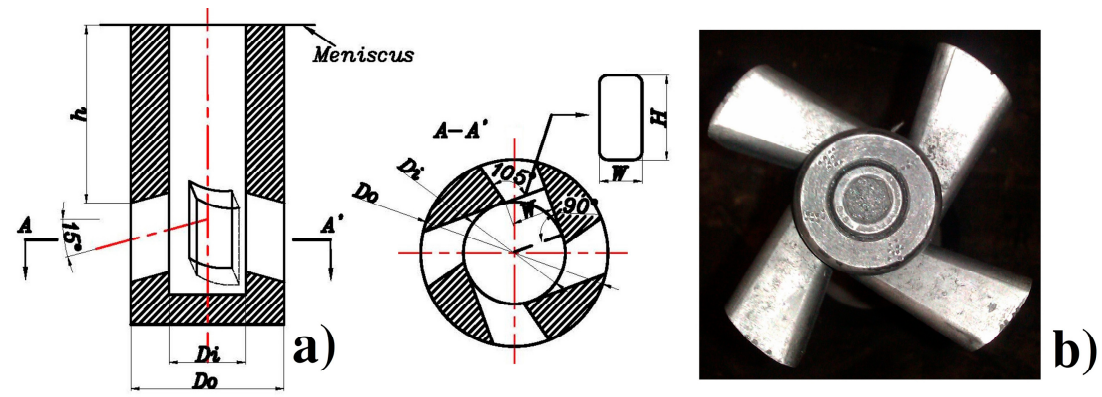

Figure 1. Geometric schematic (a) and its inner manufacture mold (b) of the swirling flow nozzle (SFN).

Table 2. Main geometrical dimensions of SFN and bilateral-port nozzle.

\begin{tabular}{ccccccc}
\hline Parameters & $\begin{array}{c}\text { Inner } \\
\text { Diameter } \\
(\boldsymbol{D i}), \mathbf{m}\end{array}$ & $\begin{array}{c}\text { External } \\
\text { Diameter } \\
(\mathbf{D o}), \mathbf{m}\end{array}$ & $\begin{array}{c}\text { Outlet } \\
\text { Height } \\
(\boldsymbol{H}), \mathbf{m}\end{array}$ & $\begin{array}{c}\text { Outlet } \\
\text { Width } \\
(\boldsymbol{W}), \mathbf{m}\end{array}$ & $\begin{array}{c}\text { Outlet } \\
\text { Angle, deg }\end{array}$ & $\begin{array}{c}\text { Immersion } \\
\text { Depth, m }\end{array}$ \\
\hline Swirling flow nozzle & 0.050 & 0.1 & 0.045 & 0.022 & 15 & 0.10 \\
Bilateral-port nozzle & 0.050 & 0.1 & 0.050 & 0.040 & 15 & 0.10 \\
\hline
\end{tabular}

Table 3. Thermal physical properties and boundary conditions employed in the simulation.

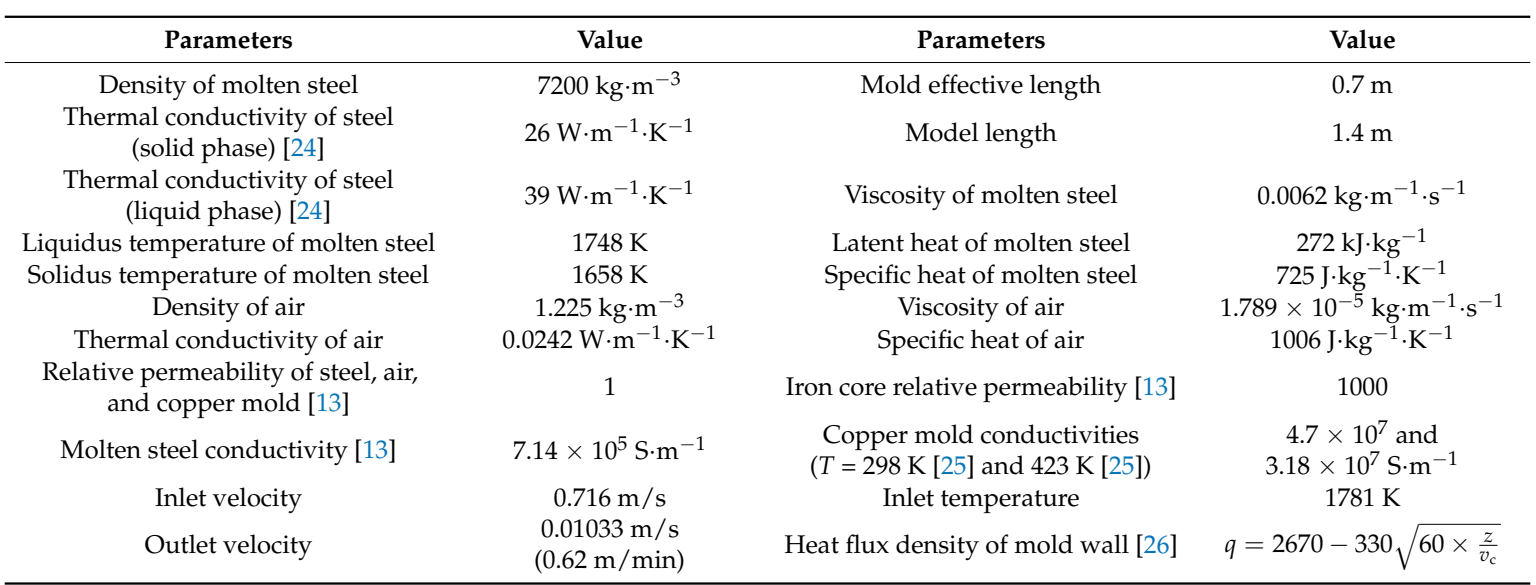

For the electromagnetic model, the three phase alternating current, with the phase difference in $2 \pi / 3$ rad, was applied to the coils of M-EMS. Magnetically flux parallel boundary was applied on the external surfaces of the surrounding air cylinder within diameter of $1.6 \mathrm{~m}$.

For the heat transfer and VOF model, at the inlet, its velocity was calculated by using the mass conservation between the inlet and the outlet according to casting speed. The values of the corresponding turbulent kinetic energy and dissipation rate were calculated based on the semiempirical expressions [12]. Fixed molten steel volume fraction of 1 and casting temperature of $1778 \mathrm{~K}$ were also adopted. At the mold outlet, the pressure-out condition and the fully developed flow conditions were adopted. The normal gradients of all variables and the volume fraction of molten steel were set to be 0 . At the free surface, the molten steel and gas (air) phases are considered as a continuum in VOF models with a pressure-out condition for the gas phase. No-slip condition and standard "wall 
functions" near the wall were employed for all walls. A thermal boundary condition was applied on the mold wall with the heat flux density as functions of distance, $z$, from the meniscus, and casting speed, $v_{c}$, according to the work of Savage [26].

\subsubsection{Computational Procedure}

During the calculation process, the melt flow and heat transfer in the strand were simulated by the computational fluid dynamics code Fluent. The electromagnetic field in the bloom strand, calculated by the finite element code ANSYS (ANSYS 17.0, ANSYS, Inc., Canonsburg, PA, USA) adopting the harmonic simulation, was imported into the Fluent code as a momentum source term through the coordinate interpolation algorithm. Moreover, the PISO algorithm was chosen for the velocity iterations and the PRESTO for pressure during iterative calculation of the coupled model by Fluent code. The criterion for convergence was established when the calculated enthalpy residual should be less than $10^{-6}$ and the other item convergence limit is $10^{-4}$.

\section{Results and Discussions}

\subsection{Electromagnetic Field}

Figure 2 displays the comparison between the calculated and the measured variations in magnetic flux densities (MFDs) along the strand central axis and the stirrer center under different running currents and copper mold temperatures. Here, the measured MFDs are obtained by a CT-3 Teslameter. It is seen that the calculated MFDs are in good agreement with the measured values under the offline state (without strand, only air inside the copper mold). The MFD at the strand center first increases and then decreases along the casting direction, which matches well with the result measured by Trindade et al. [25] The MFD at the stirrer center nearly has a linear relation with the running current of M-EMS, wherein every $100 \mathrm{~A}$ increase in the current will bring an increment of $0.0025 \mathrm{~T}$ in the MFD. It is also observed that the calculated MFDs at higher running currents $(I=600 \mathrm{~A}$ and $700 \mathrm{~A})$ are a bit larger than the measured values, which seems to be reasonable because of that the stirrer efficiency will be lower with larger current intensity.
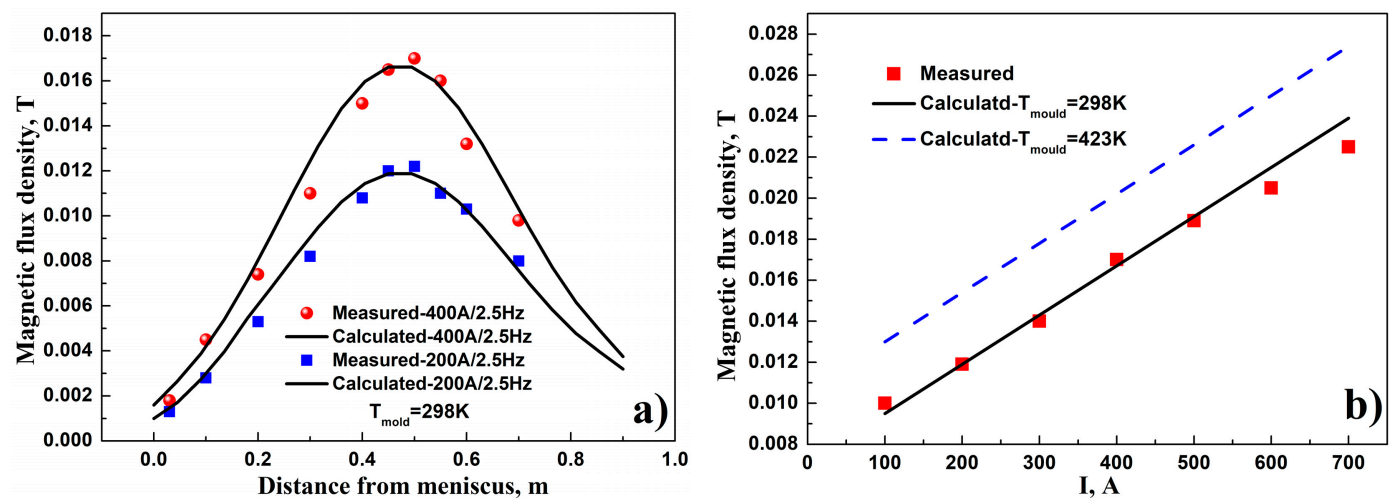

Figure 2. Comparison between the calculated and the measured variations in magnetic flux densities along the strand central axis (a) and at the stirrer center under different running currents and copper mold temperatures $(\mathbf{b})$.

The online running mold temperature, however, is higher (typically ranging from $453 \mathrm{~K}$ to $553 \mathrm{~K}$ on the mold inner face $[25,27])$ than that under the offline state, which leads to a higher MFD in the inner stand because of the lower electrical conductivity of copper. To meet the actual CC conditions, the electromagnetic field under the recommended copper mold temperature of $423 \mathrm{~K}$ [26] was calculated. Figure $2 \mathrm{~b}$ shows the calculated stirrer center MFDs under different running currents of M-EMS and copper mold temperatures. An increment of $0.0034 \mathrm{~T}$ in the MFD at the stirrer center is observed when the temperature of copper mold increases from $298 \mathrm{~K}$ to $423 \mathrm{~K}$ in the simulations. 
Accordingly, the electromagnetic field calculated under the mold temperature of $423 \mathrm{~K}$ was adopted in the following coupled model.

\subsection{Fluid Flow and Heat Transfer}

Figure 3 gives flow patterns, liquid fraction contours on the $Y=0 \mathrm{~m}$ plane and 3-D streamlines of molten steel at the upper part of strand under the respective adoption of SFN and bilateral-port nozzle plus with M-EMS. Figure 4 displays variations in stirring velocity ( $V_{y}, Y$-velocity component) at the location of $X=0.165 \mathrm{~m}$ on the $Y=0 \mathrm{~m}$ plane along casting direction under the two corresponding cases above. It is seen that an opposite stirring mode in the mold cavity can be observed under the case of the SFN plus with M-EMS. Here, an upper swirling flow in the anti-clockwise direction with the maximum stirring velocity in $0.05 \mathrm{~m} / \mathrm{s}$ is generated because of the tangential geometrical feature of outlets (shown in Figure 1) at the strand cross section. Simultaneously, the other swirling flow generated by the M-EMS in the clockwise direction within the maximum stirring velocity of $0.15 \mathrm{~m} / \mathrm{s}$ is formed at the lower part of the mould. Under this situation, a mixed zone with a distance ranging from $0.110 \mathrm{~m}$ to $0.218 \mathrm{~m}$ from the meniscus appears because of the two swirling flows with opposite direction along the casting direction.

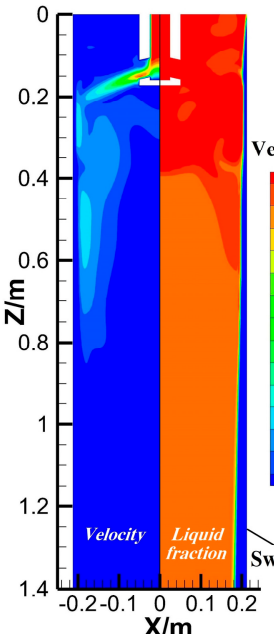

$\mathrm{X} / \mathrm{m}$

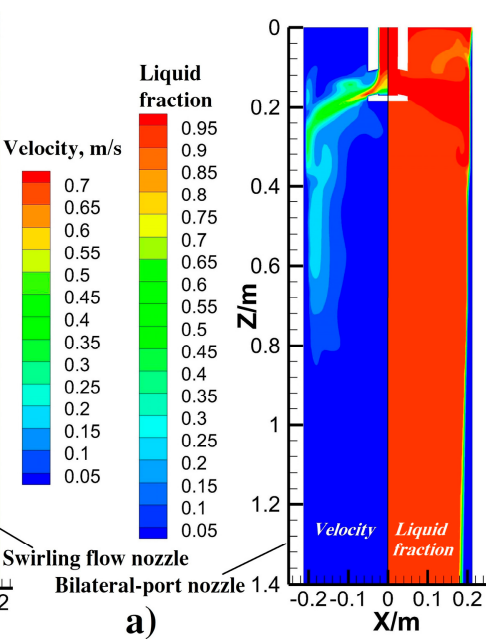

a)

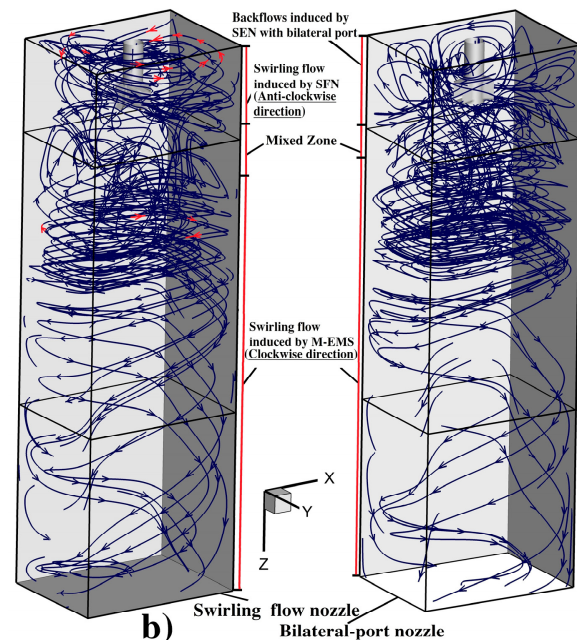

b)

Bilateral-port nozzle

Figure 3. Flow patterns, liquid fraction distributions (a) on the $Y=0 \mathrm{~m}$ plane and 3-D streamlines of molten steel (b) at the upper part of the strand under the respective adoption of the SFN and bilateral-port nozzle plus with in-mold electromagnetic stirring (M-EMS).

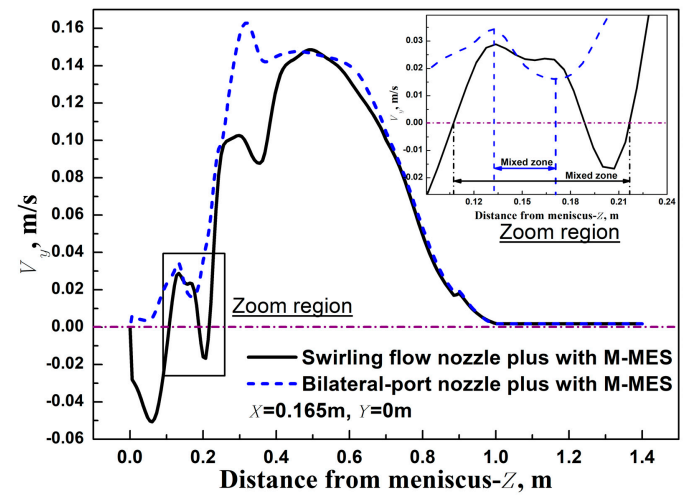

Figure 4. Variations in $Y$-velocity component at the location of $X=0.165 \mathrm{~m}$ on the $Y=0 \mathrm{~m}$ plane along the casting direction under different feeding modes.

Under the condition of bilateral-port nozzle plus with M-EMS, the bulk flow, supplied by the nozzle side port, impinges on the initial solidification shell. And then, a backflow within the radial 
pattern is formed at the upper part of the mold because of the confines of the shell and meniscus. Under the action of M-EMS, a swirling flow in the clockwise direction within the maximum stirring velocity of $0.162 \mathrm{~m} / \mathrm{s}$ is observed at the lower part of the mold. In this case, a mixed zone with a distance ranging from $0.132 \mathrm{~m}$ to $0.169 \mathrm{~m}$ from the meniscus appears because of the converting flow pattern along the casting direction.

Moreover, as compared to the case of bilateral-port nozzle plus with M-EMS, the strand center liquid fraction at the mold exit $(Z=0.7 \mathrm{~m}$ ) reduces from 0.945 to 0.895 (corresponding undercooling degree at the mold exit center increases from $4.95^{\circ} \mathrm{C}$ to $9.45^{\circ} \mathrm{C}$ ) by adopting the SFN plus with M-EMS because of the sufficient stirring in the mold cavity, which is beneficial to the further improvement of the melt superheat dissipation.

To compare metallurgical performances between the SFN and the bilateral-port nozzle plus with M-EMS, a sequence casting period that includes six heats for spring steel, 65Mn, was employed. The SFN and the bilateral-port nozzle were installed at the I and V strands, respectively, to insure the same casting condition. Table 4 lists the detailed operation conditions of industrial tests, wherein the types of M-EMS and F-EMS are all rotational.

Table 4. Main technique parameters during the continuous casting (CC) process.

\begin{tabular}{|c|c|c|c|}
\hline Parameters & Value & Parameters & Value \\
\hline Sectional dimension & $320 \times 425 \mathrm{~mm}^{2}$ & Strand adopted swirling flow nozzle & I \\
\hline Casting speed & $0.62 \mathrm{~m} / \mathrm{min}$ & Strand adopted bilateral-port nozzle & $\mathrm{II} / \mathrm{III} / \mathrm{IV} / \mathrm{V}$ \\
\hline Steel grade & $65 \mathrm{Mn}$ & $\begin{array}{c}\text { Running current and frequency of } \\
\text { F-EMS }\end{array}$ & $600 / 5 \mathrm{~Hz}$ \\
\hline $\begin{array}{l}\text { Running current and } \\
\text { frequency of M-EMS }\end{array}$ & $500 \mathrm{~A} / 2.5 \mathrm{~Hz}$ & Centre location of M-EMS & $\begin{array}{l}0.465 \mathrm{~m} \text { (below the } \\
\text { meniscus) }\end{array}$ \\
\hline Height of M-EMS & $0.40 \mathrm{~m}$ & $\begin{array}{l}\text { Inner and external diameter of } \\
\text { M-EMS }\end{array}$ & $0.836 \mathrm{~m} / 1.236 \mathrm{~m}$ \\
\hline
\end{tabular}

Figure 5 shows the sampling schematic diagram for acid etching and wet chemical analysis. For the acid etching process, the machined longitudinal sample is dipped in hydrochloric acid with temperature in $343 \mathrm{~K}$ for $18 \mathrm{~min}$ to obtain the casting section morphology. For the wet chemical analysis, filing samples are gained by using a 4-mm drill in diameter up to a depth of $8 \mathrm{~mm}$. Among these, the distance between the two adjacent filing samples is set as $15 \mathrm{~mm}$.

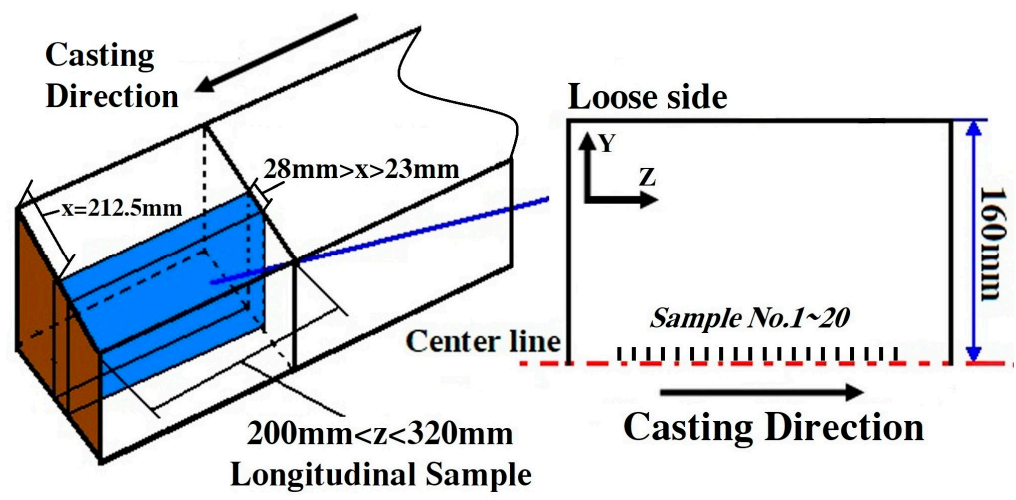

Figure 5. Sampling schematic diagram for acid etching and wet chemical analysis.

Figure 6 presents the longitudinal section morphologies of the as-cast bloom under the respective adoption of SFN and bilateral-port nozzle plus with M-EMS. Figure 7 shows variations in carbon segregation, calculated by Equation (14), at the strand center along the casting direction under the two corresponding cases above. As compared to the case of the bilateral-port nozzle plus with M-EMS, the soundness and centerline segregation of the castings can be improved remarkably by adopting 
the SFN combined with M-EMS. The fluctuation range of the carbon segregation along the casting direction reduces from 0.16 to 0.06 because of the excellent superheat dissipation effect in the mold cavity under the case of SFN plus with M-EMS.

$$
r_{i}=C_{i} / C_{i, o}
$$

where the $C_{i}$ and $C_{i, 0}$ are the local and the initial concentration of the solute element $i$ respectively, and $r_{i}$ is the segregation degree.
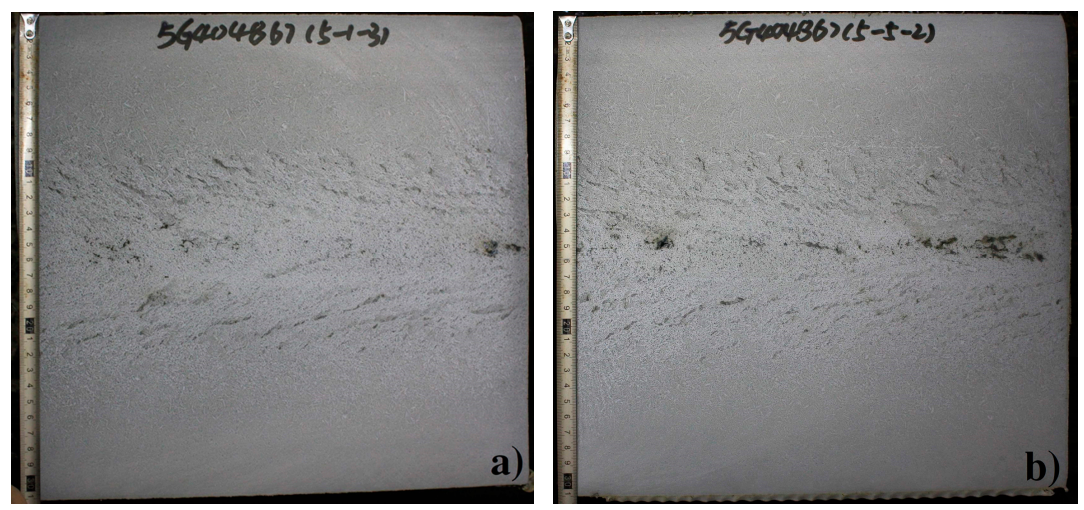

Figure 6. Longitudinal section morphologies of the as-cast bloom under the respective adoption of SFN (a) and bilateral-port nozzle (b) plus with M-EMS.

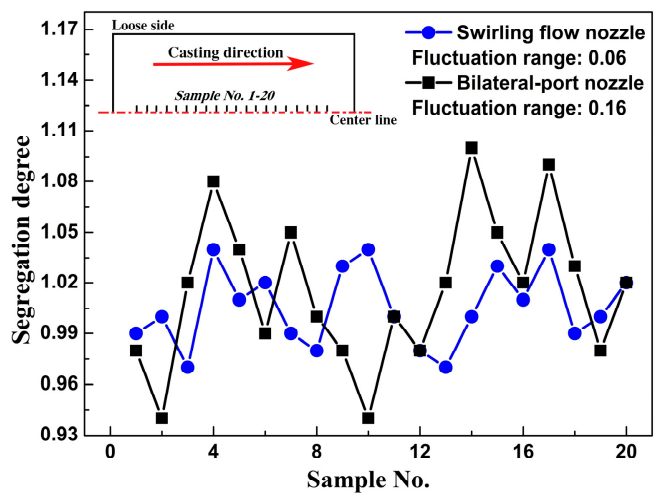

Figure 7. Variations in carbon segregation at the strand center along the casting direction.

\subsection{Level Fluctuation and Flow Condition below the Meniscus}

Figure 8 indicates the free surface profiles at the symmetric plane of the casting narrow face $(Y=0 \mathrm{~m})$ under the respective adoption of SFN and bilateral-port nozzle plus with M-EMS. It is shown that the free surface profile strongly depends on the melt flow condition below the meniscus. The wave crests are all presented near the mold wall under the two above cases due to the ascending flow produced by the jet flow from the side ports. However, as compared to the case of a bilateral-port nozzle plus with M-EMS, the magnitude of level fluctuation at the free surface reduces from $5.6 \mathrm{~mm}$ to $2.3 \mathrm{~mm}$ because of the opposite stirring mode generated by combining the SFN with M-EMS in the mold cavity. 


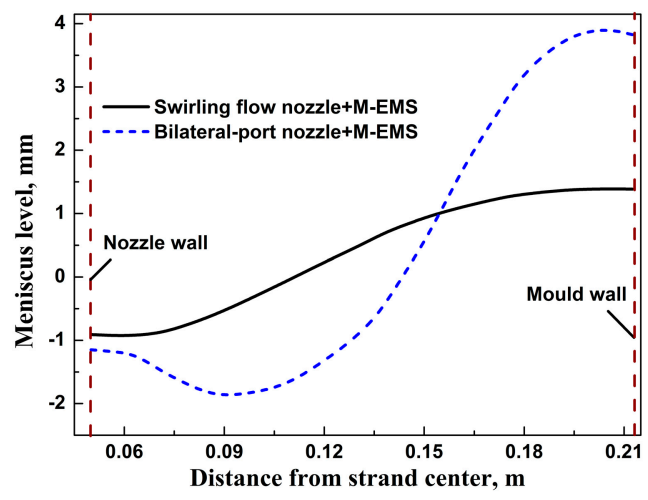

Figure 8. Free surface profiles at the $Y=0 \mathrm{~m}$ plane under the respective adoption of SFN and bilateral-port nozzle plus with M-EMS.

To get better a understanding of the flow conditions below the meniscus, Figure 9a gives variations in the melt velocities in the $X\left(V_{x}\right.$, radial velocity) and $Y\left(V_{y}\right.$, stirring velocity) components along the $X$-axis direction at the $0.005 \mathrm{~m}$ below the meniscus $(Z=0.005 \mathrm{~m})$ on the $Y=0 \mathrm{~m}$ plane. The corresponding melt velocity vectors at the $Z=0.005 \mathrm{~m}$ plane under the different feeding modes mentioned above is shown in Figure 9b. A horizontal swirling flow can be observed near the meniscus under the adoption of the SFN plus with M-EMS. Nevertheless, vortex and impact flows are formed near the nozzle external wall under the case of bilateral-port nozzle plus with M-EMS because of the backflow of the upper recirculation roll as shown in the Figure 3b. As compared to the SFN plus with M-EMS, it is shown that the maximum $V_{x}$ of molten steel below the meniscus increases from $0.031 \mathrm{~m} / \mathrm{s}$ to $0.125 \mathrm{~m} / \mathrm{s}$ when adopting the bilateral-port nozzle plus with M-EMS. This will increase the occurrence probability of slag entrainment. The $V_{y}$ of molten steel below the meniscus exhibits the maximum value of $0.098 \mathrm{~m} / \mathrm{s}$ under the case of SFN plus with M-EMS, which is almost equal to that under the case of a bilateral-port nozzle plus with M-EMS.

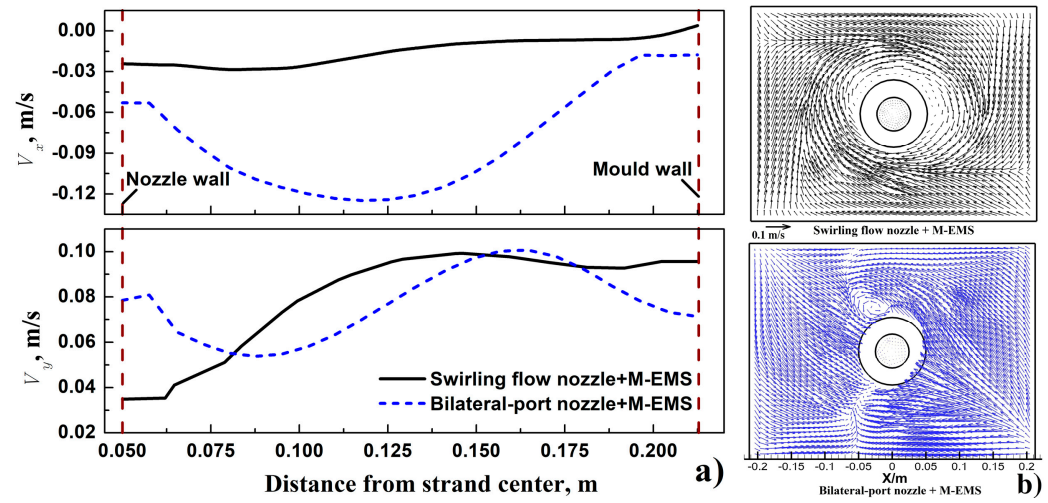

Figure 9. Variations (a) in melt radial $\left(V_{x}\right)$ and tangential $\left(V_{y}\right)$ velocity components along the $X$-axis direction at the $0.005 \mathrm{~m}$ below meniscus on the $Y=0 \mathrm{~m}$ plane, and melt velocity vectors $(\mathbf{b})$ at the $\mathrm{Z}=0.005 \mathrm{~m}$ plane under different feeding modes.

Figure 10 displays the comparison between the external surface topographies of the used SFN and bilateral-port nozzle after a sequence casting period including six heats in total, wherein the duration of a heat is $45 \mathrm{~min}$. As compared to the SFN, a deeper erosive slag line is observed on the external wall of the bilateral-port nozzle. According to the simulated results from Figures 8 and 9 , the height of the meniscus level, the impact flow with a large melt radial velocity, and the vortex flow near the external wall of the nozzle are the main formation factors of the deeper erosive slag line for the bilateral-port nozzle as compared to that of the SFN. Based on the discussion above, it can be concluded that the 
opposite stirring mode generated under the condition of SFN plus with M-EMS can build a steady bulk flow below the meniscus in the mold cavity.
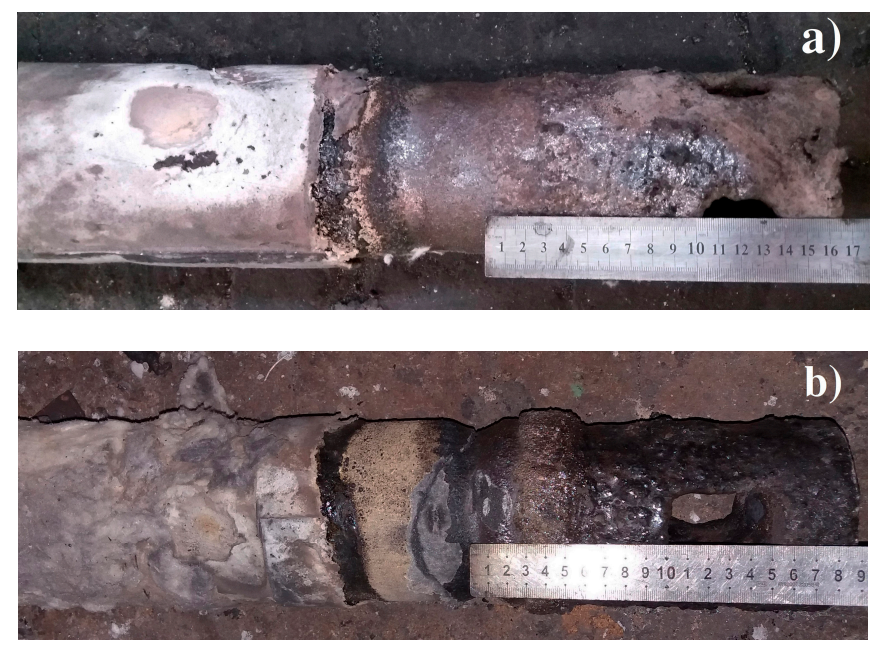

Figure 10. Comparison between the external wall topographies of the used SFN (a) and bilateral-port nozzle (b) after a sequence casting period.

\section{Conclusions}

Metallurgical behaviors in the mold cavity upon the respective adoption of SFN and bilateral-port nozzle plus with M-EMS have been numerically and experimentally investigated. The main conclusions can be summarized as follows.

1. The opposite stirring mode in the mold cavity can be formed by adopting SFN plus with M-EMS. Here, a swirling flow in the anti-clockwise direction generated by SFN, and the other swirling flow in the clockwise direction induced by M-EMS are observed at the areas with a distance ranging from $0 \mathrm{~m}$ to $0.11 \mathrm{~m}$ and $0.218 \mathrm{~m}$ to $1.4 \mathrm{~m}$ from the meniscus, respectively.

2. As compared to the case of a bilateral-port nozzle plus with M-EMS, the soundness and centerline segregation of the as-cast bloom can be improved remarkably, and the fluctuation range of carbon segregation at the strand axis reduces from 0.16 to 0.06 because of the better superheat dissipation effect in the mold cavity by adopting the SFN plus with M-EMS.

3. The opposite stirring mode generated by the SFN plus with M-EMS can build a steady bulk flow below the meniscus in the mold cavity. The magnitude of mold level reduces from $5.6 \mathrm{~mm}$ to $2.3 \mathrm{~mm}$, as compared to the case of the bilateral-port nozzle plus with M-EMS.

4. The formation reason for the deep erosive slag line on the external wall of the bilateral-port nozzle can contribute to the higher meniscus level, the impact flow with a larger melt radial velocity, and the vortex flow near the nozzle wall when compared to the case of SFN plus with M-EMS.

Author Contributions: H.S. conceived and designed the experiments; L.L. provided methodology and resource; C.L. performed the experiments and analyzed the data; H.S. wrote the paper.

Funding: This research was funded by National Natural Science Foundation of China (Grant No. 51704078), and Province Natural Science Fund of Guangdong (Grant No. 2017A030313312).

Acknowledgments: The authors greatly appreciate the support from National Natural Science Foundation of China (Grant No. 51704078), Province Natural Science Fund of Guangdong (Grant No. 2017A030313312), University key platform funding projects of Guangdong education department (Grant No. gg041002) Engineering technology research center project of Foshan City (Grant No. 20172010018) and Talent research start-up program of Foshan university (Grant No. gg040942).

Conflicts of Interest: The authors declare no conflict of interest. 


\section{References}

1. Fang, Q.; Ni, H.; Zhang, H.; Zhang, H.; Ye, F. Effects of EMS induced flow on solidification and solute transport in bloom mold. Metals 2017, 7, 72. [CrossRef]

2. Sun, H.; Zhang, J. Study on the macrosegregation behavior for the bloom continuous casting: Model development and validation. Metall. Mater. Trans. B 2014, 45, 1133-1149. [CrossRef]

3. Kholmatov, S.; Takagi, S.; Jonsson, L.; Jonsson, P.; Yokoya, S. Development of flow field and temperature distribution during changing divergent angle of the nozzle when using swirl flow in a square continuous casting billet mould. ISIJ Int. 2007, 47, 80-87. [CrossRef]

4. Tsukaguchi, Y.; Nakamura, O.; Jönsson, P.; Yokoya, S.; Tanaka, T.; Hara, S. Design of Swirling Flow Submerged Entry Nozzles for Optimal Head Consumption between Tundish and Mold. ISIJ Int. 2007, 47, 1436-1443. [CrossRef]

5. $\quad$ Li, D.; Su, Z.; Chen, J.; Wang, Q.; Yang, Y.; Nakajiama, K.; Marukawa, K.; He, J. Effects of Electromagnetic Swirling Flow in Submerged Entry Nozzle on Square Billet Continuous Casting of Steel Process. ISIJ Int. 2013, 53, 1187-1194. [CrossRef]

6. Li, D.; Su, Z.; Marukawa, K.; He, J. Simulation on effect of divergent angle of submerged entry nozzle on flow and temperature fields in round billet mold in electromagnetic swirling continuous casting process. J. Iron Steel Res. Int. 2014, 21, 159-165. [CrossRef]

7. Svensson, J.K.S.; Memarpour, A.; Ekerot, S.; Brabie, V.; Jonsson, G. Studies of new coating materials to prevent clogging of submerged entry nozzle (SEN) during continuous casting of Al killed low carbon steels. Ironmak. Steelmak. 2017, 44, 117-127. [CrossRef]

8. Mohammadi-Ghaleni, M.; Zaeem, M.A.; Smith, J.D.; O'Malley, R. Comparison of CFD simulations with experimental measurements of nozzle clogging in continuous casting of steels. Metall. Mater. Trans. B 2016, 47, 3384-3393. [CrossRef]

9. Sun, H.; Zhang, J. Effect of feeding modes of molten steel on the mould metallurgical behavior for round bloom casting. ISIJ Int. 2011, 51, 1657-1663. [CrossRef]

10. Sun, H.; Li, L. Application of swirling flow nozzle and investigation of superheat dissipation casting for bloom continuous casing. Ironmak. Steelmak. 2016, 43, 228-233. [CrossRef]

11. Ludlow, V.; Normanton, A.; Anderson, A.; Thiele, M.; Ciriza, J.; Laraudogoitia, J.; Knoop, W.V. Strategy to minimise central segregation in high carbon steel grades during billet casting. Ironmak. Steelmak. 2005, 32, 68-74. [CrossRef]

12. Fang, Q.; Ni, H.; Zhang, H.; Wang, B.; Lv, Z. The effects of a submerged entry nozzle on flow and initial solidification in a continuous casting bloom mold with electromagnetic stirring. Metals 2017, 7, 146. [CrossRef]

13. Trindade, L.B.; Nadalon, J.E.A.; Contini, A.C.; Barroso, R.C. Modeling of Solidification in Continuous Casting Round Billet with Mold Electromagnetic Stirring (M-EMS). Steel Res. Int. 2017, 88, 1600319. [CrossRef]

14. Liu, H.; Xu, M.; Qiu, S.; Zhang, H. Numerical simulation of fluid flow in a round bloom mold with in-mold rotary electromagnetic stirring. Metall. Mater. Trans. B 2012, 43, 1657-1675. [CrossRef]

15. Zhang, H.; Ni, H.; Li, Y.; Zhao, Z. Numerical simulation on level fluctuation in bloom casting mold with electromagnetic stirring. In Proceedings of the Conference of the South African Advanced Materials Initiative, Vanderbijlpark, South Africa, 23-26 October 2018.

16. Willers, B.; Barna, M.; Reiter, J.; Eckert, S. Experimental Investigations of Rotary Electromagnetic Mould Stirring in Continuous Casting Using a Cold Liquid Metal Model. ISIJ Int. 2017, 57, 468-477. [CrossRef]

17. Hirayama, R.; Fujisaki, K. Combined system of AC and DC electromagnetic field for stabilized flow in continuous casting. IEEE Trans. Magn. 2005, 41, 4042-4044. [CrossRef]

18. Hirayama, R.; Fujisaki, K.; Yamada, T. Dual in-mold electromagnetic stirring in continuous casting. IEEE Trans. Magn. 2004, 40, 2095-2097. [CrossRef]

19. Cho, M.J.; Park, E.B.; Kim, S.W. Shield for improving wavy meniscus in the billet continuous casting mold with electromagnetic stirring. ISIJ Int. 2010, 50, 1180-1184. [CrossRef]

20. Geng, X.; Li, X.F.; Liu, F.B.; Li, H.; Jiang, Z. Optimisation of electromagnetic field and flow field in round billet continuous casting mould with electromagnetic stirring. Ironmak. Steelmak. 2015, 42, 675-682. [CrossRef]

21. Sun, H.; Li, L.; Wu, X.; Liu, C. Effect of subsurface negative segregation induced by M-EMS on componential homogeneity for bloom continuous casting. Metall. Res. Technol. 2018, 115. [CrossRef] 
22. Hirt, C.W.; Nichols, B.D. Volume of fluid (VOF) method for the dynamics of free boundaries. J. Comput. Phys. 1981, 39, 201-225. [CrossRef]

23. Brackbill, J.U.; Kothe, D.B.; Zemach, C. A continuum method for modeling surface tension. J. Comput. Phys. 1992, 100, 335-354. [CrossRef]

24. Ebisu, Y. A numerical method of macrosegregation using a dendritic solidification model, and its applications to directional solidification via the use of magnetic fields. Metall. Mater. Trans. B 2011, 42, 341-369. [CrossRef]

25. Trindade, L.B.; Vilela, A.C.F.; Filho, A.F.F.; Vihena, M.T.M.B. Numerical model of electromagnetic stirring for continuous casting billets. IEEE Trans. Magn. 2002, 38, 3658-3660. [CrossRef]

26. Savage, J.; Pritchard, W.H. The problem of rupture of the billet in the continuous casting of steel. J. Iron Steel Inst. 1954, 178, 269-277.

27. Meng, Y.; Thomas, B.G. Heat-transfer and solidification model of continuous slab casting: $\mathrm{CON}_{1} \mathrm{D}$. Metall. Mater. Trans. B 2003, 34, 685-705. [CrossRef]

(C) 2018 by the authors. Licensee MDPI, Basel, Switzerland. This article is an open access article distributed under the terms and conditions of the Creative Commons Attribution (CC BY) license (http:/ / creativecommons.org/licenses/by/4.0/). 